\title{
Two novel sodium channel inhibitors from Heriaeus melloteei spider venom differentially interacting with mammalian channel's isoforms ${ }^{\text {is }}$
}

\author{
Bert Billen ${ }^{\mathrm{a}}$, Alexander Vassilevski ${ }^{\mathrm{b}}$, Anton Nikolsky ${ }^{\mathrm{b}}$, Jan Tytgat ${ }^{\mathrm{a}}$, Eugene Grishin ${ }^{\mathrm{b}, *}$ \\ ${ }^{a}$ Laboratory of Toxicology, University of Leuven, Campus Gasthuisberg, OEN 2, P.O. Box 922, Herestraat 49, 3000 Leuven, Belgium \\ ${ }^{\mathrm{b}}$ Shemyakin and Ovchinnikov Institute of Bioorganic Chemistry, Russian Academy of Sciences, Miklukho-Maklaya, 16/10, 117997 Moscow, Russian Federation
}

\section{A R T I C L E I N F O}

\section{Article history:}

Received 13 March 2008

Received in revised form 20 May 2008

Accepted 30 May 2008

Available online 7 June 2008

\section{Keywords:}

Spider venom

Neurotoxin

Inhibitor cystine knot

Sodium channel inhibitor

\begin{abstract}
A B S T R A C T
Two new polypeptide toxins named $\mathrm{Hm}-1$ and $\mathrm{Hm}-2$ were isolated from the venom of the crab spider Heriaeus melloteei. These toxins consist of 37 and 40 amino acid residues, respectively, contain three intramolecular disulfide bonds, and presumably adopt the inhibitor cystine knot motif. Hm-1 is C-terminally amidated and shows a low degree of homology to spider toxins agelenin and $\mu$-agatoxin-II, whereas $\mathrm{Hm}-2$ has no relevantly related peptide sequences. $\mathrm{Hm}-1$ and $\mathrm{Hm}-2$ were found to act on mammalian voltage-gated $\mathrm{Na}^{+}$channels. Both toxins caused a strong decrease of $\mathrm{Na}^{+}$current peak amplitude, with $\mathrm{IC}_{50}$ values of 336.4 and $154.8 \mathrm{nM}$, respectively, on $\mathrm{Na}_{\mathrm{V}} 1.4$. Hm-1 and $\mathrm{Hm}-2$ did not shift the voltage-dependence of activation, nor did they change the kinetics of fast inactivation of the $\mathrm{Na}^{+}$currents. Interestingly, both toxins negatively shifted the steady-state inactivation process, which might have important functional consequences in vivo. However, this hyperpolarizing shift cannot by itself explain the observed inhibition of the $\mathrm{Na}^{+}$current, indicating that the two presented toxins could provide important structural information about the interaction of polypeptide inhibitors with voltage-gated $\mathrm{Na}^{+}$channels.
\end{abstract}

(c) 2008 Elsevier Ltd. All rights reserved.

\section{Introduction}

Voltage-gated $\mathrm{Na}^{+}\left(\mathrm{Na}_{\mathrm{V}}\right)$ channels constitute a large superfamily of membrane-spanning glycoproteins that form ion-conducting pores with a high selectivity for $\mathrm{Na}^{+}$ ions. They play a crucial role in processes of eliciting and propagating action potentials in electro-excitable cells as

Abbreviations: HPLC, high-performance liquid chromatography; MALDI, matrix-assisted laser desorption ionization; MS, mass spectrometry; STX, saxitoxin; TFA, trifluoroacetic acid; TTX, tetrodotoxin; $\mathrm{Na}_{\mathrm{V}}$ channel, voltage-gated sodium channel.

\footnotetext{
The protein sequence data reported in this paper will appear in the Uniprot Knowledgebase under the accession numbers P85505 (Hm-1) and P85506 (Hm-2).

* Corresponding author. Tel.: +7 495 3366540; fax: +7 4953307301.

E-mail address: grev@ibch.ru (E. Grishin).
}

well as homeostasis maintenance (Catterall, 2000). Highaffinity interaction with some specific ligands allows identifying, purifying and characterizing these membrane proteins. Peptides from scorpion, sea anemone, cone snail and spider venoms, in particular, have become a new generation of high-precision tools that serve to investigate ion conductivity, spatial structure, and pharmacological characteristics of $\mathrm{Na} v$ channels (Corzo and Escoubas, 2003; Grishin, 1999; Honma and Shiomi, 2006; Rodriguez de la Vega and Possani, 2005; Terlau and Olivera, 2004). In spite of recent success, structure and physiological role of many types of $\mathrm{Na}_{\mathrm{v}}$ channels are yet unknown. Therefore, finding new specific ligands is an urgent problem that is directed on deciphering molecular aspects of ion channel function.

$\mathrm{Na}_{\mathrm{V}}$ channels consist of a major pore-forming $\alpha$-subunit $(\sim 260 \mathrm{kDa})$ and one or more smaller auxiliary $\beta$-subunits (30-40 kDa). Expression of the $\alpha$-subunit alone is sufficient to construct a functional Nav channel, whereas $\beta$-subunits modulate the kinetics and voltage-dependence of channel 
gating and influence channel localization and cell adhesion (Yu and Catterall, 2003). To this moment, nine different mammalian $\mathrm{Na}_{v}$ channel isoforms ( $\left.\mathrm{Na}_{v} 1.1-\mathrm{Na}_{v} 1.9\right)$ were cloned, from which the first eight have been functionally expressed. In addition, a 10th related isoform $\left(\mathrm{Na}_{\mathrm{x}}\right)$ was cloned, which may also act as a $\mathrm{Na}^{+}$channel (Catterall et al., 2005). The $\alpha$-subunit is composed of four homologous domains (DI-DIV), each of which contains six transmembrane segments (S1-S6). In the cell membrane, the first and the fourth domains are located in close proximity to each other, resulting in a clockwise assembly of the four domains which enclose the ion-conducting gateway. The extracellular connecting loop between transmembrane segments S5 and S6 in every domain dips into the membrane and is described to form part of the selectivity pore of the channel. This selectivity pore acts as a filter attributing to the high selectivity of the channel for $\mathrm{Na}^{+}$ions. The fourth transmembrane segment (S4) of each domain contains several positively charged amino acid residues and acts as a voltage sensor. Depolarization of the cell membrane causes an outward movement of the voltage sensors, which results in conformational changes of the channel and initiates activation. A short sequence of hydrophobic amino acid residues (Ile-Phe-Met) in the intracellular loop that connects DIII and DIV mediates the fast inactivation of the channel (Catterall, 2000; Denac et al., 2000).

Toxins can exert their actions on $\mathrm{Na}_{\mathrm{V}}$ channels through different mechanisms that can be split into two groups: they can inhibit $\mathrm{Na}^{+}$conduction of the channel by physically occluding the ion-conducting pore ( $\mathrm{Na}_{\mathrm{V}}$ channel blockers), or they can alter the channel gating kinetics and voltagedependence by interacting with a region of the channel that changes conformation during channel gating (gating modifiers). On the $\alpha$-subunit of mammalian $\mathrm{Na}_{V}$ channels, at least seven ligand-binding receptor sites have been identified using toxins that act on the channel in different manners. Site 1 toxins (tetrodotoxin TTX, saxitoxin STX, and $\mu$-conotoxins) block $\mathrm{Na}^{+}$conductance by occluding the channel pore. Most $\mathrm{Na}_{\mathrm{V}}$ channel isoforms are reversibly blocked by nanomolar concentrations of STX and TTX, hence they are called tetrodotoxin-sensitive (TTX-S); isoforms $\mathrm{Na}_{\mathrm{v}}$ 1.5, Nav1.8 and Nav1.9 are blocked by significantly higher concentrations of TTX and are referred to as tetrodotoxin-resistant (TTX-R). Site 2 toxins (batrachotoxin, grayanotoxin) cause permanent activation by an inhibition of the channel's fast inactivation and a hyperpolarizing shift in the voltage-dependence of activation; site 3 toxins ( $\alpha$ scorpion toxins, sea anemone toxins and some spider toxins) inhibit fast channel inactivation; site 4 toxins ( $\beta$-scorpion toxins and some spider toxins) shift voltagedependence of activation to more hyperpolarizing voltages; site 5 toxins (brevetoxins and ciguatoxins) shift activation and inhibit fast inactivation; site 6 toxins ( $\delta$-conotoxins) as well as site 7 toxins (pyrethroids or DDT) cause inhibition of the fast channel inactivation (Cestele and Catterall, 2000; Leipold et al., 2005; Wang and Wang, 2003).

To date, numerous polypeptide $\mathrm{Na}_{\mathrm{V}}$ channel gating modifiers have been isolated and characterized from the venom of various animals (Bosmans and Tytgat, 2007a,b; Catterall et al., 2007; Corzo et al., 2007; de la Vega and Possani, 2007; Nicholson et al., 2004; Priest et al., 2007). In contrast, only a limited number of polypeptide toxins were reported to physically block $\mathrm{Na}_{\mathrm{V}}$ channels. Among these, the earlier described $\mu$-conotoxins from cone snails block $\mathrm{Na}^{+}$currents in a manner similar to TTX and share an overlapping but not identical binding site with TTX (Li and Tomaselli, 2004). Genuine $\mathrm{Na}_{\mathrm{V}}$ channel blockers from spider venoms are represented by just a few examples. These include hainantoxins I and III-V from the spider Selenocosmia hainana (Li et al., 2003; Xiao and Liang, 2003a,c), huwentoxins I and IV from Selenocosmia huwena (Peng et al., 2002; Wang et al., 2007; Xiao et al., 2008) and Tx 1 from Phoneutria nigriventer (Diniz et al., 2006; Martin-Moutot et al., 2006). Most of these spider toxins are thought to interact with receptor site 1 on the Nav channel and block $\mathrm{Na}^{+}$conductance via a mechanism similar to that of TTX and STX.

In this article, we describe the first two $\mathrm{Na}_{\mathrm{V}}$ channel inhibitors isolated from the venom of crab spider Heriaeus melloteei, designated as $\mathrm{Hm}-1$ and $\mathrm{Hm}-2$, both active on $\mathrm{Na}_{\mathrm{V}}$ channels at concentrations in the $10^{2} \mathrm{nM}$ range.

\section{Materials and methods}

\subsection{Toxin purification}

Crude venom of the spider H. melloteei Simon, 1886 (Araneae, Thomisidae) was purchased from Fauna Laboratories, Ltd. (Republic of Kazakhstan) ${ }^{1}$. Lyophilized venom was dissolved in distilled water (10 $\mathrm{mg}$ in $1 \mathrm{ml}$ ) and separated by reverse-phase high-performance liquid chromatography (HPLC) on a Jupiter $C_{5}$ column $(4.6 \times 150 \mathrm{~mm}$, Phenomenex, USA) using a 60-min linear gradient of acetonitrile $(0-60 \%)$ in $0.1 \%(v / v)$ aqueous trifluoroacetic acid (TFA) at a flow rate of $1 \mathrm{ml} / \mathrm{min}$. At the second stage of separation, the active fractions were exposed to HPLC on a Luna $\mathrm{C}_{8}$ column $(4.6 \times 150 \mathrm{~mm}$, Phenomenex $)$ using a 60 -min linear gradient $(30-70 \%)$ of solvent B (50\% (v/v) acetonitrile, 20\% (v/v) isopropanol and 0.1\% TFA) at a flow rate of $1 \mathrm{ml} / \mathrm{min}$. At each stage eluate absorbance was monitored at $280 \mathrm{~nm}$.

\subsection{Reduction of disulfide bonds and modification of thiol groups}

Purified toxins were dried on a vacuum concentrator and redissolved in $40 \mu \mathrm{l}$ of $0.5 \mathrm{M}$ Tris- $\mathrm{HCl}(\mathrm{pH} 8.5), 6 \mathrm{M}$ guanidine hydrochloride and 3 mM EDTA. A 150-fold molar excess of 1,4-dithiothreitol was added to the mixtures. Probes were sealed and incubated at room temperature for $18 \mathrm{~h}$. Alkylation was performed by addition of 4vinylpyridine solution in $50 \%(\mathrm{v} / \mathrm{v}$ ) isopropanol (a threefold excess with respect to dithiothreitol), the reaction was carried out at room temperature for $15 \mathrm{~min}$ in the dark. The modified polypeptides were separated by reverse-phase HPLC on a Jupiter $C_{5}$ column $(2 \times 150 \mathrm{~mm}$, Phenomenex $)$ using a 60 -min linear gradient of acetonitrile (15-60\%) in $0.1 \%$ TFA at a flow rate of $0.3 \mathrm{ml} / \mathrm{min}$. Eluate absorbance was monitored at $210 \mathrm{~nm}$.

\footnotetext{
1 SPP Code - A125CH1. Could represent a novel species. Classification provided by Andrey Feodorov from Fauna Laboratories, Ltd.
} 


\subsection{Protein sequencing}

The N-terminal amino acid sequences of the alkylated peptides were determined on a Procise Model 492 protein/peptide sequencer (Applied Biosystems, USA) according to the manufacturer's protocol.

\subsection{Endoproteinase Glu-C digestion}

Digestion of $1 \mathrm{nmol}$ of pure alkylated peptides was performed with $0.2 \mu \mathrm{g}$ of endoproteinase Glu-C (Sigma) in $20 \mu \mathrm{l}$ of $50 \mathrm{mM}$ ammonium bicarbonate buffer ( $\mathrm{pH} 8.0$ ). Probes were incubated for $4 \mathrm{~h}$ at $37^{\circ} \mathrm{C}$. Peptide fragments were separated on a Jupiter $C_{5}$ column $(2 \times 150 \mathrm{~mm})$. A 60 -min linear gradient of acetonitrile (0-60\%) in 0.1\% TFA at a flow rate of $0.3 \mathrm{ml} / \mathrm{min}$ was used. Eluate absorbance was monitored at $210 \mathrm{~nm}$.

\section{5. $\mathrm{CNBr}$ cleavage}

One nanomole of pure alkylated peptides was dissolved in $20 \mu \mathrm{l}$ of $80 \%$ aqueous TFA and $1 \mu \mathrm{l}$ of $5 \mathrm{M} \mathrm{CNBr}$ in acetonitrile was added. The samples were incubated for $18 \mathrm{~h}$ at room temperature in the dark. The reaction was terminated by diluting the mixture with $1 \mathrm{ml}$ of distilled water, and the samples were dried using a vacuum evaporator. Reaction products were separated on a Jupiter $C_{5}$ column as described in Section 2.4.

\subsection{Mass spectrometry (MS) analysis}

The molecular masses of the peptides were measured by matrix-assisted laser desorption ionization (MALDI) mass spectrometry (MS), a MALDI LR (Micromass UK Ltd., UK) instrument was used. Calibration was performed using either a ProteoMass peptide and protein MALDI-MS calibration kit (mass range of 700-66,000 Da) or a ProteoMass peptide MALDI-MS calibration kit (mass range of 700-3500 Da) (both from Sigma). Molecular masses were determined in a linear positive ion mode. 2,5-Dihydroxy benzoic acid $(10 \mathrm{mg} / \mathrm{ml}$ in $70 \%(\mathrm{v} / \mathrm{v})$ acetonitrile, $0.1 \%$ TFA) matrix was used.

\subsection{Expression of voltage-gated sodium channels in Xenopus laevis oocytes}

For expression in Xenopus oocytes, the cDNA encoding rNav1.2 and mNav1.6 was subcloned into vector pLCT1 and the rNav1.4 cDNA was subcloned into vector pUI-2. For in vitro transcription, these plasmids were linearized with NotI. The $\mathrm{h} \beta_{1} / \mathrm{pGEM}-\mathrm{HE}$ construct was linearized with NheI. Next, capped cRNAs were synthesized from the linearized plasmid using the T7 mMESSAGE-mMACHINE transcription kit (Ambion, USA). The hNav1.5/pSP64T, $\mathrm{rNa}_{\mathrm{V}} 1.8 / \mathrm{pBSTA}$ and $\mathrm{r} \beta_{1} / \mathrm{pSP} 64 \mathrm{~T}$ plasmids were linearized with XbaI, NotI and EcoRI, respectively, and transcribed with the SP6 mMESSAGE-mMACHINE transcription kit (Ambion, USA).

Stage V-VI oocytes were harvested from the ovarian lobes of anaesthetized female $X$. laevis frogs as described previously (Liman et al., 1992). Oocytes were injected with $50 \mathrm{nl}$ of cRNA (ratio $\alpha$ : $\beta$-subunit of $1: 1$ ) at a concentration of $1 \mathrm{ng} / \mathrm{nl}$ using a micro-injector (Drummond Scientific, USA). The incubation solution for the oocytes contained (in $\mathrm{mM}$ ): $\mathrm{NaCl} 96, \mathrm{KCl} 2, \mathrm{CaCl}_{2} 1.8, \mathrm{MgCl}_{2} 2$ and HEPES 5 (pH 7.4) and was supplemented with 50 mg/l gentamycin sulfate.

\subsection{Electrophysiological recordings}

Currents were recorded using the two-electrode voltage clamp method. The experiments were performed at room temperature $\left(18-22^{\circ} \mathrm{C}\right.$ ) using a GeneClamp 500 amplifier (Axon Instruments, USA) controlled by a pClamp data acquisition system (Axon Instruments, USA). Whole cell currents from oocytes were recorded 2-5 days after injection. The voltage and current electrodes were filled with $3 \mathrm{M} \mathrm{KCl}$. Resistances of both electrodes were kept as low as possible $(<1.0 \mathrm{M} \Omega$ ). The elicited currents were sampled at $10 \mathrm{kHz}$ and filtered at $1 \mathrm{kHz}$ using a four-pole low-pass Bessel filter. To eliminate the effect of the voltage drop across the bath grounding electrode, the bath potential was actively controlled by a two-electrode bath clamp. Leak subtraction was performed using a $-\mathrm{P} / 4$ protocol. The bath solution was composed of (in $\mathrm{mM}$ ): $\mathrm{NaCl} 96, \mathrm{KCl}$ 2, $\mathrm{CaCl}_{2}$ 1.8, $\mathrm{MgCl}_{2} 2$ and HEPES 5 ( $\mathrm{pH} 7.4$ ).

To electrophysiologically characterize the toxins Hm-1 and $\mathrm{Hm}-2$, the following voltage protocols were applied. (1) From a holding potential of $-90 \mathrm{mV}$, current traces were elicited by 100 -ms depolarizations at a frequency of $0.2 \mathrm{~Hz}$, to the voltage of maximal activation of the $\mathrm{Na}_{\mathrm{V}}$ channel isoform in control conditions. (2) To assess the concentration dependency of the toxin-induced inhibitory effects, dose-response curves were constructed for both toxins. In the presence and absence of a range of concentrations, current traces were evoked as described above. The percentage of toxin-induced inhibition of the $\mathrm{Na}^{+}$current peak amplitudes was plotted against the logarithm of applied concentrations and fitted with the Hill equation to obtain the $\mathrm{IC}_{50}$ value (i.e. the toxin concentration which produces $50 \%$ of the maximal effect) of the effects of Hm-1 and Hm-2. From the Hill equation, the Hill coefficient (i.e. the number of molecules necessary to block one channel) was obtained. (3) In order to investigate the effects of both toxins on the voltage-dependence of activation, current traces were evoked at $0.2 \mathrm{~Hz}$ from a holding potential of $-90 \mathrm{mV}$, by $100-\mathrm{ms}$ depolarizations from -70 to $40 \mathrm{mV}$ with $5-\mathrm{mV}$ increments. The $\mathrm{Na}^{+}$conductances were calculated from the Ohm's law, normalized and plotted as a function of voltage. To obtain an activation curve, this data set was fitted with the Boltzmann equation, yielding the $V_{\mathrm{g}}$ value (i.e. the voltage of half maximal activation). (4) The effects of Hm-1 and $\mathrm{Hm}-2$ on the steady-state inactivation were determined by a standard double-pulse protocol in which, from a holding potential of $-90 \mathrm{mV}, 100-\mathrm{ms}$ conditioning pulses from -120 to $10 \mathrm{mV}$ with $5-\mathrm{mV}$ increments were applied. The conditioning pulse was followed immediately by a $100-\mathrm{ms}$ test pulse to the voltage of maximal activation of the $\mathrm{Na}_{V}$ channel in control conditions. The repetition interval was $5 \mathrm{~s}$. The peak $\mathrm{Na}^{+}$currents elicited in the test pulse were normalized, plotted against voltage and fitted with the Boltzmann equation, yielding the $V_{\mathrm{h}}$ 
value (i.e. the voltage of half maximal steady-state inactivation).

All data were analyzed with Origin software (OriginLab Corp., USA). To determine statistically significant differences between two means, the Student's $t$-test was used with a probability level of $95 \%$. All data are presented as mean \pm standard error.

\section{Results}

Initial screening of a collection of spider venoms identified the crab spider $H$. melloteei (family Thomisidae) ${ }^{1}$ venom to possess a potent blocking activity towards different $\mathrm{Na}_{\mathrm{V}}$ channel isoforms. This venom was used to identify novel polypeptide toxins affecting $\mathrm{Na}_{\mathrm{V}}$ channels via a bioassay-guided purification.

\subsection{Toxin isolation and purification}

The new toxins were isolated using a two-step reversephase HPLC. In the first step, crude $H$. melloteei venom was fractionated on a Jupiter $C_{5}$ column (Fig. 1A). Separation produced several broad peaks that were combined into 10 fractions and tested. The active fractions 6 and 7 were further separated on a Luna $\mathrm{C}_{8}$ column using a mixture of acetonitrile and isopropanol as the mobile phase (Fig. 1B and $\mathrm{C}$ ). The active fractions were named $\mathrm{Hm}-1$ and $\mathrm{Hm}-2$ and their $95 \%$ purity was verified by analytical chromatography and MALDI-MS. The measured molecular masses of the new peptides were 4171.9 and 4555.3 Da.

\subsection{Amino acid sequence analysis}

Alkylation of non-reduced molecules with 4-vinylpyridine revealed no free thiol groups in the native peptides as indicated by MS analysis. Complete amino acid sequences of the peptides (see Fig. 2) were identified by a combination of Edman degradation, selective proteolysis and MS. Direct $\mathrm{N}$-terminal sequencing of reduced and alkylated peptides provided 37 and 40 amino acid long sequences for $\mathrm{Hm}-1$ and $\mathrm{Hm}-2$, respectively, both containing six half-cystine residues. To verify the deduced sequences, the reducedalkylated peptides were hydrolyzed with endoproteinase Glu-C and cyanogen bromide. The measured molecular mass of Hm-1 C-terminal CNBr (TLSCTRNF, 1045.2 Da) and Glu-C (FWSGPWCCAGKCKLNVWSMTLSCTRNF, 3546.1 Da) fragments differed from the calculated values (1046.2 and $3547.3 \mathrm{Da}$, respectively) by $1 \mathrm{Da}$. It was concluded that $\mathrm{Hm}-1$ is post-translationally modified and has an amidated C-terminal residue. For other peptide fragments the measured molecular masses matched the calculated values. Thus, Hm-1 and Hm-2 were determined as single-chain polypeptides containing 37 and 40 amino acid residues, respectively, including six cysteines involved in three intramolecular disulfide bridges (Fig. 2).

\subsection{Effects of Hm-1 and $\mathrm{Hm}-2$ on $\mathrm{Na}_{V}$ channels}

Using the two-electrode voltage clamp technique, the effects of Hm-1 and $\mathrm{Hm}-2$ were assessed on cloned $\mathrm{Nav}$ channel isoforms expressed in Xenopus oocytes. First,
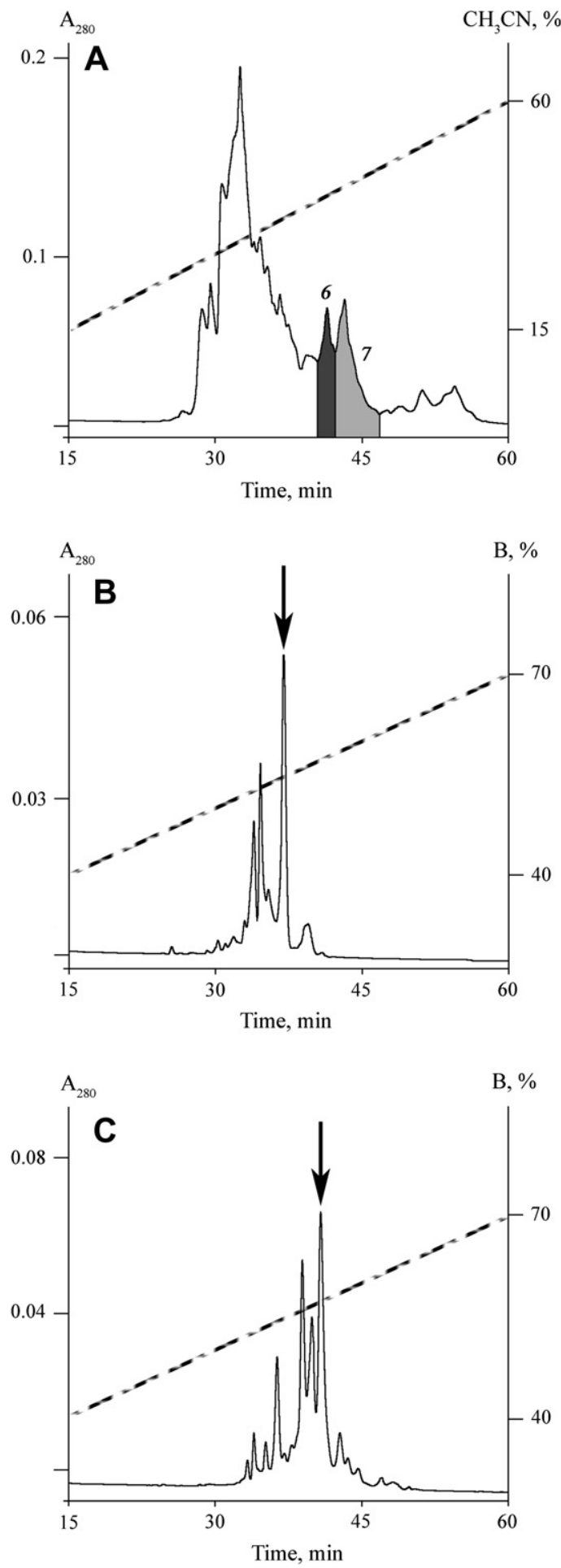

Fig. 1. Toxin purification. (A) Separation of $20 \mu \mathrm{l}$ of $H$. melloteei crude venom using reverse-phase HPLC on a Jupiter $C_{5}$ column. Second step separation of fractions 6 (B) and 7 (C) on a Luna $C_{8}$ column. The active fractions are indicated with arrows. 


\section{Hm-1 GCIPYGKTCEFWSGPWCAGKCKLNVWSMTLSCTRNF-NH Hm-2 GCIPS}

Fig. 2. Amino acid sequences of Hm-1 and Hm-2 toxins. Aromatic amino acid residues are underlined, cysteine residues are shaded grey, methionine and glutamic acid residues are in bold.

Hm-1 and Hm-2 were tested on mammalian $\mathrm{Na}_{\mathrm{v}}$ channel isoforms $\mathrm{Na}_{V} 1.2, \mathrm{Na}_{V} 1.4-\mathrm{Na}_{V} 1.6$ and $\mathrm{Na}_{V} 1.8$ (Fig. 4A). At a concentration of $200 \mathrm{nM}$, both toxins significantly decreased the peak currents of all tested $\mathrm{Na}_{\mathrm{V}}$ channel isoforms, except for the TTX-R isoform Nav1.8 which was not affected $(n=3-4)$. Hm-1 blocked all other tested Nav channel isoforms with a similar potency: $200 \mathrm{nM} \mathrm{Hm}-1$ reduced the peak amplitudes of $\mathrm{Na}_{V} 1.2, \mathrm{Na}_{V} 1.4-\mathrm{Na}_{V} 1.6$ by $32.4 \pm 12.6,40.0 \pm 6.0,36.5 \pm 4.7$ and $38.7 \pm 4.6 \%$, respectively ( $n=4-12)$. Hm-2, on the other hand, appeared to exhibit a slight preference for $\mathrm{Na}_{\mathrm{V}} 1.2(64.6 \pm 7.7 \%$ of block at $200 \mathrm{nM}, \quad n=5)$ and Nav1.4 $(61.9 \pm 5.1 \%$ of block at $200 \mathrm{nM}, n=7$ ), compared to $\mathrm{Na}_{\mathrm{V}} 1.5$ and $\mathrm{Na}_{\mathrm{V}} 1.6$ (inhibition of peak amplitudes by $17.8 \pm 3.8 \%(n=6)$ and $38.7 \pm 8.2 \%$ $(n=3)$, respectively). Since the effects of Hm-1 and $\mathrm{Hm}-2$ appeared to be the most pronounced on Nav1.4, the effects of both toxins on this $\mathrm{Na}_{\mathrm{V}}$ channel isoform were investigated more into detail. A dose-response curve was constructed showing the concentration dependency of the inhibitory effects of $\mathrm{Hm}-1$ and $\mathrm{Hm}-2$ on the peak $\mathrm{Na}^{+}$currents of $\mathrm{Na}_{\mathrm{V}} 1.4$ (Fig. $4 \mathrm{~B}$ ). $\mathrm{Hm}-1$ was shown to inhibit the Nav1.4 channel with an $\mathrm{IC}_{50}$ value of $336.4 \pm 40.1 \mathrm{nM}$ ( $n=3-12$, Hill coefficient $=1.0 \pm 0.1$ ) whereas Hm-2 affects this $\mathrm{Na}_{\mathrm{V}}$ channel isoform with an $\mathrm{IC}_{50}$ value of $154.8 \pm 11.2 \mathrm{nM}(n=3-9$, Hill coefficient $=1.2 \pm 0.1)$. Both Hill coefficients suggest a one-to-one toxin-channel interaction.

\subsection{Effects of Hm-1 and $\mathrm{Hm}-2$ on the gating of $\mathrm{Na}_{V}$ channels}

In order to investigate the mechanism behind the toxininduced inhibition of Nav channels by $\mathrm{Hm}-1$ and $\mathrm{Hm}-2$, their effects on the voltage-dependence of activation and steady-state inactivation of $\mathrm{rNa}_{\mathrm{V}} 1.4$ were examined. The current-voltage relationships in control conditions and after addition of $200 \mathrm{nM} \mathrm{Hm}-1$ and $\mathrm{Hm}-2$ show that both toxins inhibit the $\mathrm{Na}^{+}$current without changing the reversal potential, indicating that the ion selectivity of the $\mathrm{Na}_{\mathrm{V}}$ channel does not change (Fig. 5A). The toxins do not shift the threshold potential of activation or voltage corresponding to maximal current. To quantify the effects of the toxins on $\mathrm{Na}^{+}$channel gating, activation and steady-state inactivation curves were constructed as described above (see Fig. 5B). The steady-state inactivation curves ( $\mathbf{\square}$ - control; $\square-200$ nM toxin) show that both toxins significantly shift the $V_{\mathrm{h}}(p<0.05)$ towards more hyperpolarized potentials. $\mathrm{Hm}-1$ causes a shift in $V_{\mathrm{h}}$ from $-53.7 \pm 0.8$ to $-59.9 \pm 1.2 \mathrm{mV}(n=3)$ and $\mathrm{Hm}-2$ shifts the $V_{\mathrm{h}}$ from $-47.4 \pm 0.5$ to $-54.4 \pm 0.8 \mathrm{mV}(n=9)$. Furthermore, the activation curves ( - control; $\bigcirc-200 \mathrm{nM}$ toxin) show that Hm-1 and Hm-2 cause a small depolarizing but nonsignificant shift in $V_{\mathrm{g}}(p>0.05)$, from $-27.8 \pm 0.5$ to $-25.7 \pm 0.3 \mathrm{mV} \quad(n=3) \quad$ and from $-22.8 \pm 0.7$ to $-19.3 \pm 0.8 \mathrm{mV}(n=9)$, respectively.

\section{Discussion}

A large number of animals are able to produce venom that contains substances acting on different targets in the nervous system such as ion channels and membrane receptors. Peptide toxins are the most useful and efficient tools used for ion channel studies because of their high affinity and specificity of action. In the present work, we investigated the primary structure and pharmacological function of $\mathrm{Hm}-1$ and $\mathrm{Hm}-2$, the first two toxins isolated from $H$. melloteei spider venom that inhibit $\mathrm{Na}_{\mathrm{v}}$ channels.

The amino acid sequences of the new toxins were established by conventional methods of protein chemistry and mass spectrometry. $\mathrm{Hm}-1$ and $\mathrm{Hm}-2$ share a primary sequence identity of $38 \%$. Similarity searches in protein sequence databases revealed that $\mathrm{Hm}-1$ shows a low degree of homology with toxins from spider venoms: agelenin (40\% identity) (Hagiwara et al., 1990; Hagiwara et al., 1991) and $\mu$-agatoxin-II (32\%) (Skinner et al., 1989) (Fig. 3). Agelenin from the spider Agelena opulenta is composed of 35 amino acid residues with three disulfide bonds. This toxin was suggested to irreversibly inhibit invertebrate presynaptic calcium channels, but the mechanism of its action is still unknown (Inui et al., 1992). $\mu$-Agatoxin-II from Agelenopsis aperta is a 37 amino acid residues-long peptide with four disulfide bonds. Its molecular target is yet unknown, but this toxin is thought to act on $\mathrm{Na}_{\mathrm{V}}$ channels (Adams et al., 1989; Omecinsky et al., 1996). In contrast to $\mathrm{Hm}-1, \mathrm{Hm}-2$ has no relevantly similar sequences in protein databases. Hm-1 and $\mathrm{Hm}-2$ each contain six highly conserved half-cystines and therefore possibly have the same disulfide-bonding pattern and similar three-dimensional structure resembling the inhibitor cystine knot (ICK) fold common to most spider neurotoxins (Pallaghy et al., 1994). Another remarkable feature of the new toxins is

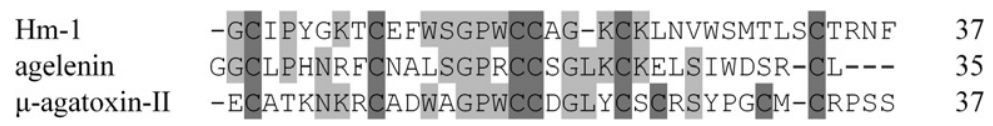

Fig. 3. Amino acid sequence alignment of Hm-1 with agelenin and $\mu$-agatoxin-II - toxins from the spiders Agelena opulenta and Agelenopsis aperta, respectively. The number of amino acid residues in the polypeptide chain of the corresponding toxin is indicated in the right column. Cysteine residues are shaded dark grey. Identical residues are shaded light grey. Alignment of $\mathrm{Hm}-2$ is not shown because of negligible sequence similarity with other known peptides. 
A

$\mathrm{Hm}-1$
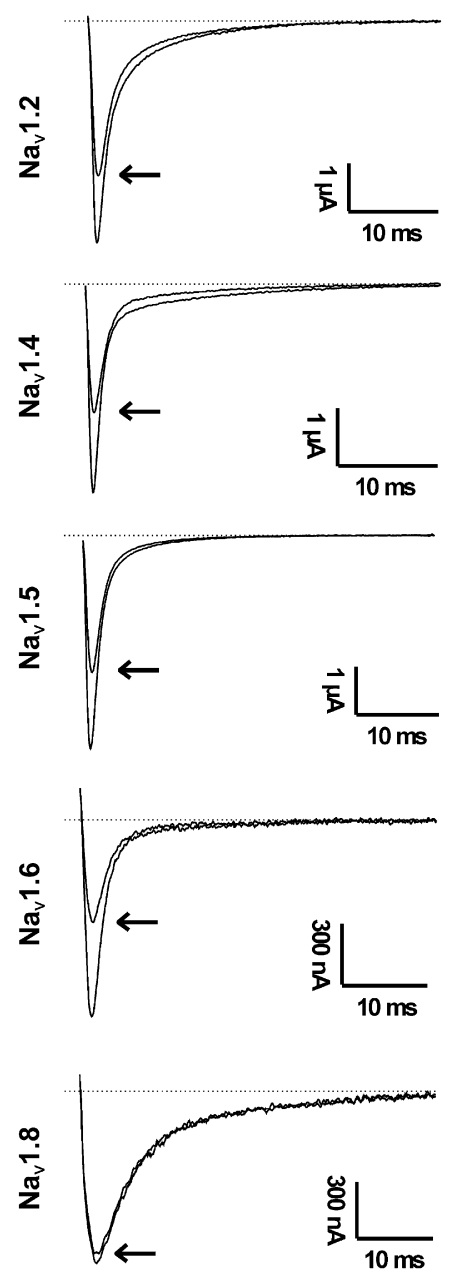

B

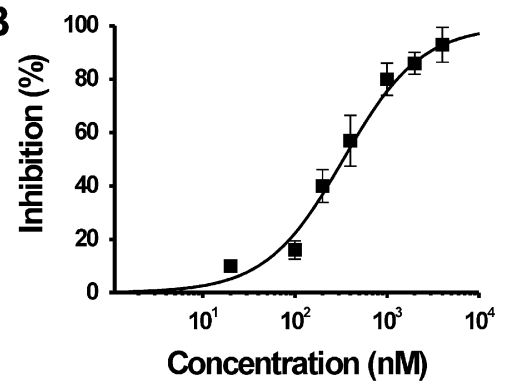

$\mathrm{Hm}-2$
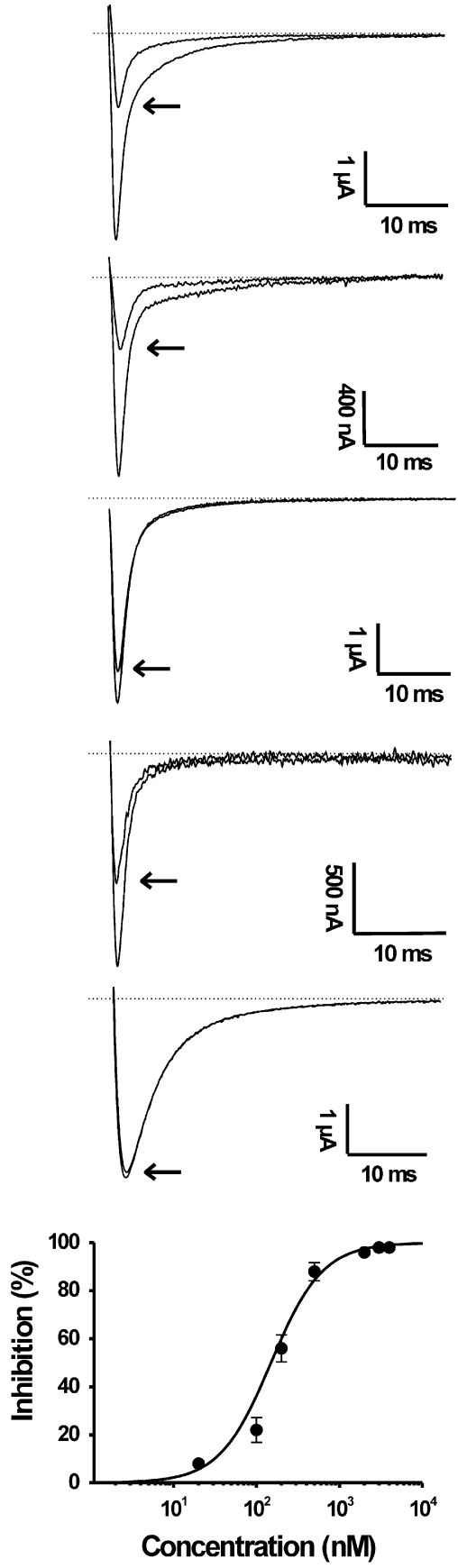

Fig. 4. Effects of Hm-1 and $\mathrm{Hm}-2$ on different mammalian $\mathrm{Na}_{\mathrm{V}}$ channel isoforms. (A) Representative current traces of cloned $\mathrm{Na} \mathrm{V}_{\mathrm{V}}$ channel isoforms $\mathrm{rNa} \mathrm{V}_{\mathrm{V}} 1.2$, rNav1.4, hNav1.5, mNav1.6 and rNav1.8 expressed in Xenopus oocytes. The arrow indicates the steady-state Na ${ }^{+}$current peak amplitude in the presence of $200 \mathrm{nM}$ toxin, with Hm-1 on the left panels and Hm-2 on the right panels. The dotted line indicates the zero-current level. (B) Dose-response curves for $\mathrm{Hm}-1$ (left panel) and Hm-2 (right panel) on rNa 1.4 . Both curves were fitted with the Hill equation, yielding IC 50 values of $336.4 \pm 40.1$ and $154.8 \pm 11.2 \mathrm{nM}$ for $\mathrm{Hm}-1$ and $\mathrm{Hm}-2$, respectively.

the high content of aromatic amino acid residues (see Fig. 2). As a result, these residues are proposed to play a special role in the interaction with channel protein via formation of hydrophobic clusters.

At present, the following $\mathrm{Nav}_{\mathrm{v}}$ channel blockers from spider venoms have been described. The hainantoxins from
S. hainana represent the first discovered family of spider peptides that selectively block $\mathrm{Na}^{+}$conductance: HNTX-I specifically acts on the para/tipE insect $\mathrm{Na}_{\mathrm{V}}$ channel (Li et al., 2003), whereas HNTX-III-V block mammalian TTX-S $\mathrm{Na} v$ channels at nanomolar concentrations (Liu et al., 2003; Xiao and Liang, 2003a,b,c). Huwentoxins I and IV from 
A

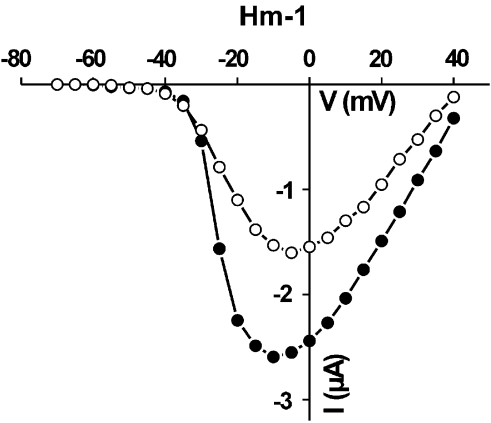

B

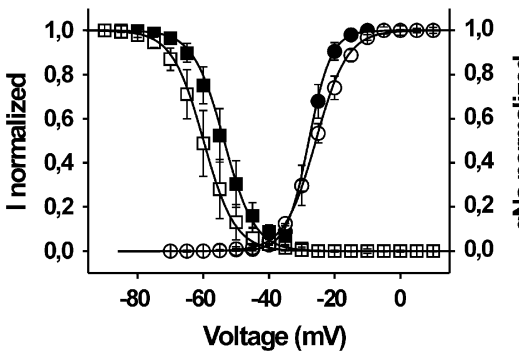

$\mathrm{Hm}-2$
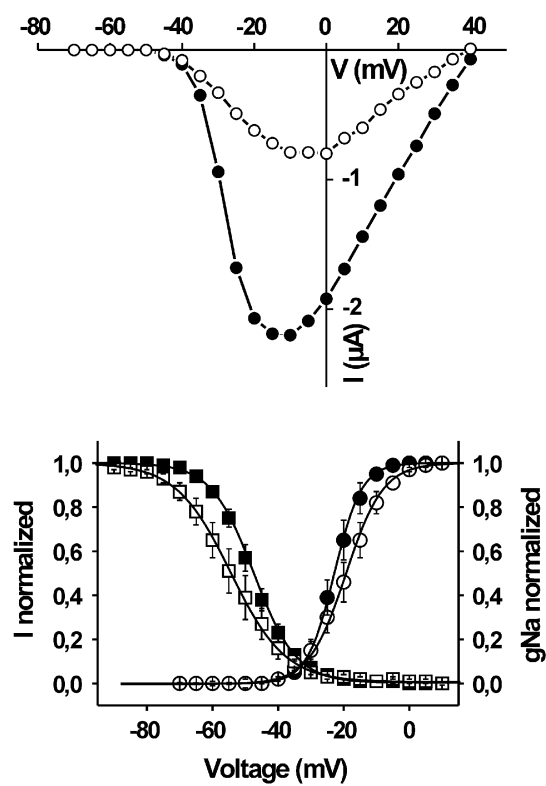

Fig. 5. Effects of Hm-1 and Hm-2 on the current-voltage relationships and voltage-dependence of steady-state inactivation and activation of rNa 1.4 . (A) Current-voltage relationships of a representative experiment in control ( $)$ and after the addition ( 0 ) of $200 \mathrm{nM} \mathrm{Hm-1}$ (left panel) and $200 \mathrm{nM} \mathrm{Hm}-2$ (right panel). (B) Voltage-dependence of steady-state inactivation and activation in control ( $\square$ and $\bullet$, respectively) and after the addition ( $\square$ and $\circ$, respectively) of 200 nM Hm-1 (left panel) and $200 \mathrm{nM} \mathrm{Hm}-2$ (right panel).

S. huwena inhibit TTX-S Nav channels in adult rat dorsal root ganglion neurons, also at nanomolar concentrations (Peng et al., 2002; Wang et al., 2007; Xiao et al., 2008). Furthermore, the structurally peculiar $P$. nigriventer toxin 1 (Tx 1) was shown to block $\mathrm{Na}_{\mathrm{V}}$ channels with a high sub-nanomolar affinity (Diniz et al., 2006; Martin-Moutot et al., 2006).

In this study, Hm-1 and Hm-2 were found to significantly inhibit cloned $\mathrm{Na}_{\mathrm{V}}$ channels expressed in Xenopus oocytes. Both toxins significantly decreased $\mathrm{Na}^{+}$current peak amplitudes of all tested TTX-S isoforms without significantly altering the fast inactivation kinetics of the $\mathrm{Na}^{+}$ currents. The TTX-S isoform $\mathrm{Na}_{V} 1.4$ appeared to be one of the most affected isoforms by both toxins, with $\mathrm{IC}_{50}$ values of $336.4 \pm 40.1$ and $154.8 \pm 11.2 \mathrm{nM}$, respectively. The current-voltage relationships (Fig. 5A) show that $\mathrm{Hm}-1$ and $\mathrm{Hm}-2$ did not change the threshold potential of activation or the voltage corresponding to maximal current. Moreover, the reversal potential of the Nav1.4 currents was not altered, indicating that the toxins did not change the ion selectivity of the Nav channel. Both Hm-1 and Hm-2 caused a small but significant hyperpolarizing shift of about $6-7 \mathrm{mV}$ in the midpoint of steady-state inactivation (Fig. 5B). Similar observations were made in electrophysiological studies with other spider toxins that inhibit $\mathrm{Na}^{+}$ channels, such as HNTX-III-V (Xiao and Liang, 2003a,b,c) and HWTX-I (Wang et al., 2007). Altogether, these results show that the mechanism of action of Hm-1 and Hm-2 differs from that of gating modifier toxins that slow the fast inactivation by binding to receptor site 3 (Bosmans and Tytgat, 2007a; Gordon et al., 2007; Nicholson et al., 2004) or shift the voltage-dependence of activation upon binding to receptor site 4 (Bosmans et al., 2007; de la Vega and Possani, 2007) of Nav channels.
The newly characterized toxins described in this article act on mammalian $\mathrm{Na}_{\mathrm{V}}$ channels at relatively high concentrations ( $10^{2} \mathrm{nM}$ range), compared to most of the listed known $\mathrm{Na}_{\mathrm{v}}$ channel inhibitors. We therefore speculate that the natural target of $\mathrm{Hm}-1$ and $\mathrm{Hm}-2$ is most probably insect $\mathrm{Na}^{+}$channels since insects constitute the natural prey of most spiders including $H$. melloteei. The originality of the presented toxins is in their pharmacological behavior, phenotypically similar to that of classical $\mathrm{Na}_{\mathrm{V}}$ channel blockers TTX and STX (Cestele and Catterall, 2000). Therefore, it seems reasonable to assume that $\mathrm{Hm}-1$ and $\mathrm{Hm}-2$ interact with the same site on $\mathrm{Na}_{\mathrm{V}}$ channels as TTX and STX, i.e. receptor site 1 , although this hypothesis definitely needs to be further supported by isotope-labeled toxin binding assays or mutagenesis studies. However, another equally plausible explanation is that $\mathrm{Hm}-1$ and $\mathrm{Hm}-2$ inhibit $\mathrm{Na}_{V}$ channels by binding to a voltage sensor loop on one of the I-IV pseudo-domains and thereby strongly stabilize the inactivated (i.e. functionally closed) state of the channel, effectively giving rise to reduced channel opening in the normal voltage range. Such a mechanism would be similar to the action of hanatoxin on $\mathrm{K}_{\mathrm{V}}$ channels (Phillips et al., 2005; Swartz, 2007). However, in the case of $\mathrm{K}_{V}$ channels, the strongly stabilizing effect on the closed state of the channel results in a decreased transition from the resting state to the open state, whereas in the case of Nav channels, the toxin promotes the inactivated state as judged from the hyperpolarizing shift seen in the steady-state inactivation curves (see Fig. 5B). Indeed, $\mathrm{Hm}-1$ and $\mathrm{Hm}-2$ do not provoke a higher block at moderate test potentials (e.g. $-30 \mathrm{mV}$ ), as compared with stronger depolarizations (e.g. $-20 \mathrm{mV}$ and more) (see Fig. 5A). In contrast, in the case of a $\mathrm{K}_{V}$ channel, the most pronounced toxin-induced block would be 
expected at more moderate depolarizations. Further experiments will be proven useful to elucidate the exact mechanism of action of both toxins.

Negligible sequence similarity to other known polypeptides allows us to propose that both $\mathrm{Hm}-1$ and $\mathrm{Hm}-2$ may belong to a new group of $\mathrm{Na}_{\mathrm{V}}$ channel inhibitors. Whether the shift of the steady-state inactivation can be viewed as a hallmark thereof remains to be seen. The newly described toxins are two interesting subjects for future structurefunction relationship studies, especially focusing on the large amount of hydrophobic residues. In this way $\mathrm{Hm}-1$ and Hm-2 could provide novel important structural information about the interaction between polypeptide inhibitors and $\mathrm{Na}_{\mathrm{v}}$ channels.

\section{Acknowledgements}

We are grateful to A.L. Goldin (University of California, Irvine, USA) for sharing $\mathrm{rNa}_{\mathrm{V}} 1.2$ and $\mathrm{mNa}_{\mathrm{V}} 1.6, \mathrm{G}$. Mandel (Stony Brook University, Stony Brook, USA) for sharing rNa 1.4 , R.G. Kallen (University of Pennsylvania, Philadelphia, USA) for sharing hNav1.5, J.N. Wood (University College, London, UK) for sharing $\mathrm{rNa}_{\mathrm{V}} 1.8$, S.H. Heinemann (Friedrich-Schiller-Universität, Jena, Germany) for sharing $\mathrm{r} \beta_{1}$ and S.C. Cannon (University of Texas, Dallas, USA) for sharing $h \beta_{1}$. We also thank Sarah Debaveye for her technical assistance in the molecular biology and Frank Bosmans, Eva Cuypers and Steve Peigneur for the helpful discussions.

This work was supported by the following grants: 05-04-50828 (Russian Foundation for Basic Research), Program of Cell and Molecular Biology of Russian Academy of Sciences, BIL05/50 (Bilateral collaboration between Flanders and the Russian Federation), G.0330.06 (F.W.O. Vlaanderen), OT-05-64 (K.U. Leuven) and UA P6/31 (Interuniversity Attraction Poles Program - Belgian State - Belgian Science Policy).

\section{Conflict of interest}

The authors of the manuscript entitled: "Two novel sodium channel inhibitors from Heriaeus melloteei spider venom differentially interacting with mammalian channel's isoforms" declare that there are no conflicts of interest associated with this work submitted to Toxicon.

\section{References}

Adams, M.E., Herold, E.E., Venema, V.J., 1989. Two classes of channel-specific toxins from funnel web spider venom. J. Comp. Physiol. A 164 (3), 333-342.

Bosmans, F., Martin-Eauclaire, M.F., Tytgat, J., 2007. Differential effects of five 'classical' scorpion beta-toxins on rNav1.2a and DmNav1 provide clues on species-selectivity. Toxicol. Appl. Pharmacol. 218 (1), 45-51.

Bosmans, F., Tytgat, J., 2007a. Sea anemone venom as a source of insecticidal peptides acting on voltage-gated $\mathrm{Na}^{+}$channels. Toxicon 49 (4), 550-560.

Bosmans, F., Tytgat, J., 2007b. Voltage-gated sodium channel modulation by scorpion alpha-toxins. Toxicon 49 (2), 142-158.

Catterall, W.A., 2000. From ionic currents to molecular mechanisms: the structure and function of voltage-gated sodium channels. Neuron 26 (1), 13-25.

Catterall, W.A., Cestele, S., Yarov-Yarovoy, V., Yu, F.H., Konoki, K., Scheuer, T., 2007. Voltage-gated ion channels and gating modifier toxins. Toxicon 49 (2), 124-141.
Catterall, W.A., Goldin, A.L., Waxman, S.G., 2005. International Union of Pharmacology. XLVII. Nomenclature and structure-function relationships of voltage-gated sodium channels. Pharmacol. Rev. 57 (4), 397-409.

Cestele, S., Catterall, W.A., 2000. Molecular mechanisms of neurotoxin action on voltage-gated sodium channels. Biochimie 82 (9-10), 883-892.

Corzo, G., Escoubas, P., 2003. Pharmacologically active spider peptide toxins. Cell. Mol. Life Sci. 60 (11), 2409-2426.

Corzo, G., Sabo, J.K., Bosmans, F., Billen, B., Villegas, E., Tytgat, J., Norton, R. S., 2007. Solution structure and alanine scan of a spider toxin that affects the activation of mammalian voltage-gated sodium channels. J. Biol. Chem. 282 (7), 4643-4652.

Denac, H., Mevissen, M., Scholtysik, G., 2000. Structure, function and pharmacology of voltage-gated sodium channels. Naunyn Schmiedebergs Arch. Pharmacol. 362 (6), 453-479.

Diniz, M.R., Theakston, R.D., Crampton, J.M., Nascimento Cordeiro, M., Pimenta, A.M., De Lima, M.E., Diniz, C.R., 2006. Functional expression and purification of recombinant Tx1, a sodium channel blocker neurotoxin from the venom of the Brazilian "armed" spider, Phoneutria nigriventer. Protein Expr. Purif. 50 (1), 18-24.

Gordon, D., Karbat, I., Ilan, N., Cohen, L., Kahn, R., Gilles, N., Dong, K., Stuhmer, W., Tytgat, J., Gurevitz, M., 2007. The differential preference of scorpion alpha-toxins for insect or mammalian sodium channels: implications for improved insect control. Toxicon 49 (4), 452-472.

Grishin, E., 1999. Polypeptide neurotoxins from spider venoms. Eur. J. Biochem. 264 (2), 276-280.

Hagiwara, K., Sakai, T., Miwa, A., Kawai, N., Nakajima, T., 1990. Complete amino acid sequence of a new type of neurotoxin from the venom of the spider, Agelena opulenta. Biomed. Res. 11, 181-186.

Hagiwara, K., Sakai, T., Miwa, A., Kawai, N., Nakajima, T., 1991. Agelenin a new neurotoxin from the venom of the spider, Agelena opulenta. Pept. Chem., 351-356.

Honma, T., Shiomi, K., 2006. Peptide toxins in sea anemones: structural and functional aspects. Mar. Biotechnol. 8 (1), 1-10.

Inui, T., Hagiwara, K., Nakajima, K., Kimura, T., Nakajima, T., Sakakibara, S., 1992. Synthesis and disulfide structure determination of agelenin: identification of the carboxy-terminus as an amide form. Pept. Res. 5, 140-144.

Leipold, E., Hansel, A., Olivera, B.M., Terlau, H., Heinemann, S.H., 2005 Molecular interaction of delta-conotoxins with voltage-gated sodium channels. FEBS Lett. 579 (18), 3881-3884.

Li, D., Xiao, Y., Hu, W., Xie, J., Bosmans, F., Tytgat, J., Liang, S., 2003. Function and solution structure of hainantoxin-I, a novel insect sodium channel inhibitor from the Chinese bird spider Selenocosmia hainana. FEBS Lett. 555 (3), 616-622.

Li, R.A., Tomaselli, G.F., 2004. Using the deadly mu-conotoxins as probes of voltage-gated sodium channels. Toxicon 44 (2), 117-122.

Liman, E.R., Tytgat, J., Hess, P., 1992. Subunit stoichiometry of a mammalian $\mathrm{K}^{+}$channel determined by construction of multimeric cDNAs. Neuron 9 (5), 861-871.

Liu, Z., Dai, J., Chen, Z., Hu, W., Xiao, Y., Liang, S., 2003. Isolation and characterization of hainantoxin-IV, a novel antagonist of tetrodotoxinsensitive sodium channels from the Chinese bird spider Selenocosmia hainana. Cell. Mol. Life Sci. 60 (5), 972-978.

Martin-Moutot, N., Mansuelle, P., Alcaraz, G., Dos Santos, R.G. Cordeiro, M.N., De Lima, M.E., Seagar, M., Van Renterghem, C., 2006. Phoneutria nigriventer toxin 1: a novel, state-dependent inhibitor of neuronal sodium channels that interacts with micro conotoxin binding sites. Mol. Pharmacol. 69 (6), 1931-1937.

Nicholson, G.M., Little, M.J., Birinyi-Strachan, L.C., 2004. Structure and function of delta-atracotoxins: lethal neurotoxins targeting the voltage-gated sodium channel. Toxicon 43 (5), 587-599.

Omecinsky, D.O., Holub, K.E., Adams, M.E., Reily, M.D., 1996. Three-dimensional structure analysis of mu-agatoxins: further evidence for common motifs among neurotoxins with diverse ion channel specificities. Biochemistry 35 (9), 2836-2844.

Pallaghy, P.K., Nielsen, K.J., Craik, D.J., Norton, R.S., 1994. A common structural motif incorporating a cystine knot and a triple-stranded beta-sheet in toxic and inhibitory polypeptides. Protein Sci. 3 (10), 1833-1839.

Peng, K., Shu, Q., Liu, Z., Liang, S., 2002. Function and solution structure of huwentoxin-IV, a potent neuronal tetrodotoxin (TTX)-sensitive sodium channel antagonist from Chinese bird spider Selenocosmia huwena. J. Biol. Chem. 277 (49), 47564-47571.

Phillips, L.R., Milescu, M., Li-Smerin, Y., Mindell, J.A., Kim, J.I., Swartz, K.J., 2005. Voltage-sensor activation with a tarantula toxin as cargo. Nature 436 (7052), 857-860.

Priest, B.T., Blumenthal, K.M., Smith, J.J., Warren, V.A., Smith, M.M., 2007. ProTx-I and ProTx-II: gating modifiers of voltage-gated sodium channels. Toxicon 49 (2), 194-201. 
Rodriguez de la Vega, R.C., Possani, L.D., 2005. Overview of scorpion toxins specific for $\mathrm{Na}^{+}$channels and related peptides: biodiversity, structure-function relationships and evolution. Toxicon 46 (8), 831-844.

Skinner, W.S., Adams, M.E., Quistad, G.B., Kataoka, H., Cesarin, B.J., Enderlin, F.E., Schooley, D.A., 1989. Purification and characterization of two classes of neurotoxins from the funnel web spider, Agelenopsis aperta. J. Biol. Chem. 264 (4), 2150-2155.

Swartz, K.J., 2007. Tarantula toxins interacting with voltage sensors in potassium channels. Toxicon 49 (2), 213-230.

Terlau, H., Olivera, B.M., 2004. Conus venoms: a rich source of novel ion channel-targeted peptides. Physiol. Rev. 84 (1), 41-68.

de la Vega, R.C., Possani, L.D., 2007. Novel paradigms on scorpion toxins that affects the activating mechanism of sodium channels. Toxicon 49 (2), 171-180.

Wang, M., Guan, X., Liang, S., 2007. The cross channel activities of spider neurotoxin huwentoxin-I on rat dorsal root ganglion neurons. Biochem. Biophys. Res. Commun. 357 (3), 579-583.
Wang, S.Y., Wang, G.K., 2003. Voltage-gated sodium channels as primary targets of diverse lipid-soluble neurotoxins. Cell. Signal. 15 (2), 151-159.

Xiao, Y., Liang, S., 2003a. Inhibition of neuronal tetrodotoxin-sensitive $\mathrm{Na}^{+}$channels by two spider toxins: hainantoxin-III and hainantoxin-IV. Eur. J. Pharmacol. 477 (1), 1-7.

Xiao, Y.C., Liang, S.P., 2003b. Inhibition of sodium channels in rat dorsal root ganglion neurons by hainantoxin-IV, a novel spider toxin. Sheng Wu Hua Xue Yu Sheng Wu Wu Li Xue Bao 35 (1), 82-85.

Xiao, Y.C., Liang, S.P., 2003c. Purification and characterization of hainantoxin-V, a tetrodotoxin-sensitive sodium channel inhibitor from the venom of the spider Selenocosmia hainana. Toxicon 41 (6), 643-650.

Xiao, Y., Luo, X., Kuang, F., Deng, M., Wang, M., Zeng, X., Liang, S., 2008. Synthesis and characterization of huwentoxin-IV, a neurotoxin inhibiting central neuronal sodium channels. Toxicon 51 (2), 230-239.

Yu, F.H., Catterall, W.A., 2003. Overview of the voltage-gated sodium channel family. Genome Biol. 4 (3), 207. 